757 PRIMARY PANCREATIC POLYPEPTIDE (PP) DEFICIENCY IN CHILDREN WITH CYSTIC FIBROSIS. William B. Zipf, Karen McCoy, and Thomas 0'Doris To. Ohio State versity, Children's Hosp., Depts Peds. and Med., Cols. OH.
Deficient PP release is seen in Prader-Willi syndrome and severe pancreatitis but not in other forms of malabsorption;this endocrine deficiency may reflect exocrine cell damage and may also influence appetite. Since PP can promote acinar cell growth and pancreatic exocrine secretion, we studied PP release in children with CF (ages 1 to $17 \mathrm{yr}$ ) and normal children as part of a more extensive study of PP in states of altered nutrition and appetite. PP was stimulated by a low protein meal $(0.2 \mathrm{gr} / \mathrm{kg})$ and 7 days later a high protein meal $(1.5 \mathrm{gr} / \mathrm{kg})$. Exocrine replacement was discontinued 3 days before the first test but not the second test. Levels of PP, glucose $(G)$ and insul in (I) were obtained at $0,5,15,30,45,60,90,120,180$ min. Mean \pm SE peak values as shown. Peak PP values were at 15 min for both groups.

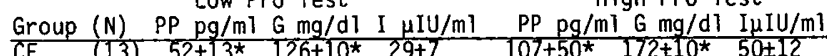

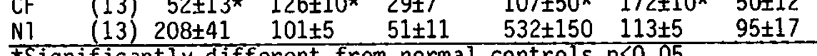
*Significantly different from normal controls p<0.05. severity of disease (NIH score). The CF group had the lowest PP severity of disease (NIH SCore). The CF group had the lowest PP
response of all groups tested in the overall project involving 109 children. This study suggests 1) PP deficiency is an early prominent abnormality in CF 2) absence of a 15 min post meal PP response of 200+ may be useful in diagnosis and screening for CF 3) severe PP deficiency per se is not necessarily associated with severe hyperphagia.

\section{GENERAL PEDIATRICS AND PEDIATRIC EDUCATION}

758 How TO ASSURE FUNDING FOR SURVIVAL OF A PEDIATRIC Louisville School of Medicine, Kosair Children's Hospital, Department of Pediatrics, Louisville, Kentucky.

Funding for departments of pediatrics has been severly affected by recent economic changes. Institutional, State, National, and Foundation support has been reduced requiring non-traditional measures to assure teaching, research, and even service needs. Departments were forced to evaluate and prioritize ali of their activities to assure maximal use of funds to assure goals. Two major approaches have emerged, Group funds to assure goals. Two major approaches have emerged, faculty, 5 fellows, and 120 staff representing administration, clerical, research technicians, and paramedical personnel has remainded intact despite reductions in excess of $10 \%$ and forced salary increases. A foundation board of 14 members, chaired by the department chairman representing sections and single persons with four community members, was established with Internal Revenue Code 501(C)(3) approval. Daily operation is carried out by the chairman and executive board. The business arm of the foundation provides total care for poverty patients, tertiary, and consult care for all groups of children and is noncompetitive with private practitioners. Extra compensation was provided for units of activity outside daily duties, irrespective of actual fees obtained for services. An unselfish, equitable, hardworking, and committed department of pediatrics has remained intact with academic performance, although stressed, not decreased and with an actual improvement on national tests by students and residents.

Predicting Strain in Pediatric Residency. Robert 759 D. Annett, Kevin J. Hartican and James A. Stockma Dept. of Peds., Northwestern U/Children's Mem. Hosp., Chicago, II.

Typically, the reactions to stress have been studied in terms of diagnosable illnesses. However, a more immediate reaction to stress is strain, the physiological \& psychological symptoms of envirommental stress. Standardized psychological instruments were mailed to 56 residents at a large children's hospital. Analyses indicated that there were no differences in strain symptoms related to sex or year in the residency. Strain was, however, highly correlated with the occupational stresses of residency ( $(00.01)$ and the degree with which respondents utilize negative coping mechanisms (p<.001) (anger, smoking, drinking, withdrawal, apathy, or taking medication). Regression analyses revealed predictors of strain. The predictors of a low level of strain included: commitment to work, favorable coping behaviors, such as use of relaxation techniques and systematic problem solving, quantity and quality of family support systems, the extent to which healthy behaviors are engaged and the level of psychological adjustment. Sixty-five percent of the variance in strain symptoms could be attributed to the above predictors. The predictors of strain during inter to the above predictors. to be as dependent on the personality traits of the individual as upon the characteristics of the occupational environment. Identification of these traits may aid program directors in achieving a better fit between residents and their training environment.
Stress in Pediatric Residency, 1984: An Occupational Hazard. Robert D. Annett, Keyin J, Bartigan, James A. Stockman IIT, Dept. Counseling Psychol., Loyola Univ, and Dept. of Peds., Northwestern U/Children's Mem. Hosp. Chicago, III.

The occupational stresses inherent in residency training have seldom been empirically evaluated. A survey designed to quantify characteristics of a residency program and its stresses mailed to 56 PL 1-3 residents at a large children's hospital. Additionally, age, sex, marital status, hours worked per week additionally, age, sex, marital status, hours worked per week measured with the Osipow \& Spokane's (1983) Occupational Envimeasured with the Osipow \& Spokane's (1983) Occupational Enviestimates six aspects of occupational stress: role overload (demands >personal resources), role insufficiency (perception of inappropriateness of skills), role ambiguity (lack of clarity of expectations), role boundry (conflicting role demands), role responsibility (perception of responsibility), and characteristics of the physical environment. Four of 6 indices were different $(p<0.01$ ) from expected normative responses. Resident stress appeared to be related to problems of role overload, role stress appeared to be related to problems of role overload,
responsibility, and the physical eviromment; while one index, role insufficiency was significantly lower than expected. Interns were the most stressed in terms of role insufficiency and ambiguity. Hours worked per week for PI-1, 2, and 3 were 89.7, 81.6 , and 74.1 respectively while average sleep on call was 2.5 hrs vs 7 at home. A "Reactions to Night call Index" showed no differences between $\mathrm{PI}-1,2$ and 3 's. Quantifying the stresses of a residency program provides a basis for the implementation of a residency program provides a
of interventions to reduce stress.

THE IMPACT OF CLINICAI APPEARATCE ON MEDICAL DECISION

761 MAKING, David Bergman. (Spon. by Charles Irwin, Jr.) Pediatrics, San Francisco, CA.

In an effort to understand how clinical appearance is utilize when making medical decisions, we presented 30 physicians with written histories and videotapes of febrile infants. The videotapes and the history were rated to be either highly predictive (HP) or weakly predictive (WP) of bacteremia. Each subject was presented with a set of 4 problems. A between subjects design was utilized to test the following combinations. VIDEOTAPE (HP) (WP)

$\begin{array}{rlll}\text { CLINICAL INFORMATION (HP) } & \text { a. } & \text { b. } \\ & \text { (WP) } & \text { c. } & \text { d. }\end{array}$

For each problem, subjects estimated the probability (P) of bacteremia and how likely they were to perform a lumbar puncture (LP), treat and/or hospitalize, seek consultation, arrange for a follow-up ( $F / U)$ visit in six hours, and obtain additional lab tests. Results showed: (I) no significant difference between combinations $a$. and $c$. for $(P)$ bacteremia or obtaining LP, consultaitons, $F / U$, or additional lab tests, (2) significantly higher values for $b$. compared to $d$. for $(P)$ bacteremia, $(p=.002)$, and obtaining LP $(\mathrm{p}=.002)$, consultations, $(\mathrm{p}=.02), \mathrm{F} / \mathrm{U}(\mathrm{p}=.008)$, and lab tests $(p=.0001)$. This study demonstrated that (1) a sick appearing patient may cause clinicians to disregard the predictivity of the history and (2) when the patient appears we11, the predictivity of the history has a significant effect on the physician decision making.

CEFACLOR (B. I.D, V T. I D.) V AMOXICILLIN IN THE TREAT762 MENT OF ACUTE OTITIS MEDIA (AOM). Kanta Bhambhani, Wayne State Univ.Sch.of Med.,Children's Hosp.of MI, Dept.of Peds. Detroit, Michigan.

A double-blind randomized study was designed to evaluate the efficacy of Cefaclor in treatment of AOM. 72 children with AOM were randomly assigned to three groups: Cefaclor $40 \mathrm{mgm} / \mathrm{kg} /$ day $B I D$, $(A, n=25)$, TID ( $B, n=23)$ Amoxicillin $40 \mathrm{mgm} / \mathrm{kg} /$ day TID $(C, n=24)$. Al1 patients were treated 14 days. The age range of the patients was lmo-16yr.Tympanocentesis (Tymp) was done on day 1 in $56 ; 19$ had tve cultures for pathogens $(A=11, B=3, C=5) .12$ patients had Tymp on day 2 of therapy for persistance of pathogens; $1(B)$ had tve culture.All organisms were sensitive to Amoxicillin and Cefaclor. Clinical response was evaluated on day $2-4$ and day 14-18 for resolution of AOM and for middle ear effusion (MEF) by pneumatoscopy and tympanometry.A1l patients had defervescence of symptoms (fever, earache and irritability)within $24 \mathrm{hrs}$. The results in the 3 roups were as follows:

Total

Lost to follow up

Adverse reaction (treatment withdrawn) 1

Evaluable

Resolution of AOM

Non-resolution of AOM

MEF at two weeks

our results show that Cefaclor is as effective as Amoxicillin in the treatment of AOM. Further, Cefaclor BID was as effective as TID regimens. BID regimen has the advantage of better patient com- 